\title{
Analysing the Correlation between English Proficiency and Academic Performance among Thai University Students
}

\author{
By Matthew Rudd ${ }^{*} \&$ Lawrence Honkiss ${ }^{\dagger}$
}

\begin{abstract}
The primary objective of this research paper is to examine the relationship between students' English language proficiency skills and academic performance across unrelated subjects from a sample population totalling 2,026 students at a private university in the surrounding areas of Bangkok. Participants in this research study comprised first, second and third year students from four separate faculties: engineering, business administration, I.T and veterinary science. This study collated English language assessment results and grade point average from all participants to analyse the correlation between the two performance-related variables via t-test significance testing (0.05) and Pearson's correlation coefficient analysis. On the grounds of Spearman's "g" factor theory of intelligence, this paper worked on the theory that higher English performance outcomes would naturally translate into higher GPA attainments. The t-test results derived from quantitative data indicated that the means of the two sets of performance-related variables were significantly different $(\mathrm{p}<0.05)$. However, the correlation coefficient analysis revealed a highly positive relationship between English language proficiency and GPA attainments $(r=0.653)$, leading to the unequivocal observation that higher English proficiency levels were associated with higher standards of GPA across all measures; (1) year group, (2) gender, (3) faculty, and (4) the entire sample population.
\end{abstract}

Keywords: academic performance, attainment, language, proficiency.

\section{Introduction}

A number of accounts have long since claimed a positive relationship between foreign language proficiency skills, and the potential to transfer higher degrees of performance into unrelated academic disciplines. Wiley (1985), found that college students who had studied a foreign language at school, namely Latin, German, French or Spanish, could be expected to perform at higher levels in college than their counterparts who were on the same par academically, but had not previously studied a foreign language.

Results from a separate research study proposed the positive cognitive benefits of bilingualism on academic performance in a general sense. Kessler \& Quinn (1980) at Georgetown University discovered a positive correlation between bilingualism and problem-solving skills in science. They discerned the cognitive advantage of bilingualism afforded to young learners in formulating scientific

"Doctoral Student, Philippine Christian University, Philippines.

${ }^{\dagger}$ Academic Coordinator, Philippine Christian University (PCU), Philippines. 
hypotheses and discovering solutions to problems. The findings discovered that bilingual children constantly outperformed monolingual children in the quality of hypotheses generated and in the complexity of written language. One reasoned argument cited from the same source (1980) was that children who participate in bilingual programmes develop two linguistic perspectives and can make the positive interactions of cognitive functioning and language development more fully operative. However, it must be pointed out that bilingual learners naturally acquire two languages, (effectively two L1s), and the innate mental processes of such acquisition are very disparate from those involved in the academic pursuit of a second language.

Although these findings certainly are of pedagogical interest, one particular distinction must be made. The study relating to the impact of bilingualism on academic performance answers an entirely different category of research questions to those set out in this paper, given that the learning process for second language acquisition (L2) is entirely separate to that of first language acquisition (L1). No matter the complexity of the L1, infants master their native language(s) effortlessly, and in some multi-heritage family backgrounds, they are able to become simultaneously bilingual or even trilingual. Contrarily, this paper aims to examine the correlation between English language proficiency as a separate academic subject, and students' GPA from an unrelated domain. Very little detailed research coverage appears to be freely available on this matter.

\section{General Intelligence Factor}

Charles Spearman (1904) coined the term ' $g$ ' factor, which worked on the precept that all tasks on intelligence tests, whether mathematical or verbal, where influenced by this underlying $g$ factor. Spearman developed a factor analysis based on a statistical procedure of his own formulation, which tests the correlation between intelligence-associated variables that are cognitively unrelated. Namely, these measures include directions, mathematics, verbal skills, as well as the ability to perceive pitch and colours. The upshot of Spearman's data was that individuals scoring well in one given domain had also performed higher in other unrelated tasks (Myers, 2009), which points to the existence of a global factor that permeates all aspects of cognition (Gottfredson, 1998). According to behavioural geneticist Robert Plomin, aside from indicating one's general level of intelligence, the $g$ factor can also help to shape anticipations of individuals' selection processes and future vocational considerations; " $g$ is one of the most reliable and valid measures in the behavioural domain ... and it predicts important social outcomes such as educational and occupational levels far better than any other trait" (Pederson, Plomin, \& McClearn, 1994).

It has been proposed that the $g$ factor accounts for 40 to $50 \%$ of the betweenindividual performance differences on cognitive tests and composite (IQ) scores (Kamphaus et al., 2005). In addition to which, Jensen (1998) maintained that the predictive validity of $g$ is most conspicuous in the domain of scholastic performance, largely because $g$ is closely associated with the ability to learn novel material as well as understand concepts and meanings. 
Howard Gardner's Multiple Intelligence (M.I) theory includes a degree of overlap with Spearman's $g$ philosophy. In addition to measuring cognitive abilities such as musical-rhythmic (composing music), visual-spatial (spatial judgment), verbal-linguistic (words and languages), logical-mathematical (critical thinking), bodily-kinaesthetic (training responses - sports, dancing), Gardner (1999) considered certain personality characteristics as forms of intelligence such as interpersonal skills (communication and empathising) and intrapersonal skills (self-reflection). Linguistic and logical-mathematical abilities are widely accepted as forms of intelligence, and that artistic and characteristic skills have been encompassed into the MI theory as they constitute a broader scope of inherent mental abilities, which Gardner believed were overlooked in a one-dimensional testing format, such as an IQ value; "I balk at the unwarranted assumption that certain human abilities can be arbitrarily singled out as intelligence while others cannot" (Gardner, 1998).

Furthermore, Gardner (1995) maintains that any given domain (physics, chess, and music) can be realised through the use of several intelligences. Gardner also suggested that educators contemplate differentiating the teaching of content to address individuals' constitutional variations of intelligence, and to proportionately allocate more time to fewer key subjects, as opposed to broad superficial coverage taught in homogenised fashion; "... any uniform educational approach is likely to serve only a minority of children" (Gardner, 1995).

\section{The Transfer of Cognitive Skills}

A number of academics have proposed possible similarities between the nature of learning a foreign language and unrelated subjects. MacGregor \& Price (1999) suggested metalinguistic awareness enables the language user to reflect on the structural and functional features of text as an object, to make choices about how to communicate information, and to manipulate perceived units of language.... Analysing structure, making choices about representation, and manipulating expressions are (also) intrinsic to mathematics, (p. 452). Adams (2003) recognises that mathematics is not by definition classified as a language, but advances that the mental processes involved in learning mathematics and English as a foreign language are not dissimilar.

Wakefield (2000) considered mathematics to be a language given the use of abstraction to communicate (through verbal or written symbols representing ideas or images), encoding and decoding for purposes of communication, and that students learn to adhere to rules which are uniform and consistent. In addition, syntax arrangements are crucial to the representation of meaning in both subjects given that the order of symbols affects meaning. Languages often offer a range of grammatical variations to convey the same meaning, whereas mathematics may offer a variety of strategies to work out the solutions for one particular equation. As a result of this mutual cognitive influence, foreign language learning has been claimed to result in increased academic flair "in a broader sense", and research has proven that children who are exposed to a foreign language at a young age achieve higher levels of cognitive development (Bialystok \& Hakuta, 1994; Fuchsen, 
1989), because language learners show greater cognitive flexibility, superior problem solving capabilities, and, higher order thinking skills (Hakuta, 1984).

Strong evidence also indicates that time spent on foreign language study helps to reinforce the core subject areas of reading, English language literacy, social studies and maths. Foreign language learners consistently outperform control groups in core subject areas on standardised tests, often in significant fashion (Armstrong \& Rogers, 1997; Saunders, 1998; Masciantonio, 1977; Rafferty, 1986). In this research paper, all data are generated from under graduates of sciencerelated fields which usually entail a large degree of numeracy demands and mathematical logic.

\section{Literature Review}

More recently, a number of EFL related research studies have come to light, providing greater detail on research methods and data analysis. Three studies below drawn from three separate continents have been identified for discussion.

Nigeria: the first paper for discussion appeared in the Journal of Scientific Research (2009, p.490-495) which measured the English proficiency of 200 Nigerian secondary school students (109 males and 91 females) from eight random schools in Oyo and Osun states (four schools in each state). The study reviewed the correlation between students' English language skills, and how proficiency in English can predict overall academic performance. Students underwent an English Language Proficiency Test (ELPT- a standardised TOEFL paper), to gauge students listening, reading comprehension, grammar and writing skills. The students were also interviewed to test for speaking proficiency, taking account of pronunciation, style, vocabulary, grammar, syntax, fluency and accuracy. After which, the scores of the participants were collected across three core subjects: English, mathematics and biology. Subsequently, correlation coefficient analysis was used to determine the impact of English language proficiency on students' overall academic achievement.

Following the ELPT test results, the students' level of English was categorised as follows: only $4 \%$ of the sampled students failed the proficiency in English test (less than 40\%), 21.5\%: ordinary pass (40-49\%), 43\%: lower credit (50-59\%), 26\%: upper credit (60-69\%), 6.5\%: distinction (70-79\%). The mean value of the students ELPT score was $58.2 \%$, which showed that the students' proficiency of English was classified as a high average standard.

Findings revealed that there was a significant positive relationship between proficiency in English language and academic performance $(r=0.499 ; p<.05)$. The positive relationship implied that the greater the students' English language proficiency, the higher the level of overall academic performance. The dependent variable revealed that the coefficient of determination, (adjusted $R 2=0.408$, which gives the proportion of variance to be $40.8 \%$ ), meant that $40.8 \%$ of the total changes in students' academic performance were determined by the level of the students' proficiency in English language. The effect is therefore shown to be 
significant $(\mathrm{F} 1,198)=18.0 ; \mathrm{p}<.05)$, and the study concluded that $41 \%$ of the variation in students' performance is determined by students' proficiency in English.

Bangladesh: a similar study published in the ABAC Journal 5 years later (May - Aug 2014, vol. 4, p. 64-70) revealed a parallel trend. The study focused on testing students' proficiency in English across several faculties at United National University in Dakar, Bangladesh. The study sampled 90 students aged 19-24, (50 male and 40 female), from the school of Business, Science and Engineering. Students sat a 90 minute writing examination to test for grammar, reading comprehension, vocabulary and structural use of paragraphs. The assessment process also comprised a listening test and individual presentations, followed by spontaneous questioning. The results collated were compared with the students current CGPA (Cumulative Grade Point Average). Upon statistical analysis, the correlation coefficient ( 0.05 significance) of the two sets of results was calculated at 0.58 , suggesting that the more proficient the students' English, the higher their level of academic achievement.

Australia: the third EFL related study discussed in this section was published in the International Educational Journal (Vol 3, No4, 2002) and was conducted at the University of Southern Australia. The research focused on exchange students' English proficiency (measured by IELTS scores) and the respective impact on academic performance. Students are admitted on study placements based on their current GPA at their university of origin and IELTS English proficiency levels. In the year 2000, the university tested the relationship between international students' IELTS scores and their corresponding GPA. The secondary purpose behind the study was to evaluate the potential changes in student population as a consequence of increasing the IELTS entry cut-off scores from 6.0 up to 6.5 .

The research project encompassed a population of 101 foreign students, with approximately half of the students being male and half female. Furthermore, half of the sample population were postgraduate, and half undergraduate with a mean age of 25.6 years. Students were predominantly from Asian countries, chiefly China, Malaysia and Indonesia. The mean GPA was 4.87 and the IELTS entrance scores mostly ranged between 6.0 and 7.0. The outcome revealed that, for the 46 undergraduate students, a regression coefficient of +0.39 for IELTS suggested a (mild) positive relationship between IELTS and GPA; thus for every one unit increase in IELTS score, the mean GPA rose by 0.39 . Though relatively weak, a correlation nonetheless was recognised. The relationship proved to be more salient among the 55 postgraduate students, which was implied by the regression coefficient of +0.79 .

However, the enhancements in GPA seem inconsequential when considering the impact on student enrolments. The increment of 0.5 points in IELTS entrance scored would lead to a colossal $50 \%$ reduction in undergraduate admissions, and an insufferably heavier loss in post-graduate student enrolments (-67\%). Moreover, the study also contemplated the effects of raising the IELTS entry cut-off score to 7.0 for post-graduate courses. The desirable increase in GPA $(8.87 \%)$ would be 
offset by the unacceptable decline in student population (78\%), posing long-term financial infeasibility. In spite of the potential decrease in student population, the calculations maintain that raising the standards of students' IELTS admittance scores (English proficiency) naturally reflects in a higher GPA.

\section{The Significance of this Study}

The common implementation variable in each of the reviewed EFL based studies is that the participants were studying academic programmes taught in English which is a forevermore prevalent case worldwide, especially with respect to international subjects such as business administration, media studies, doctorate programmes, engineering and computer science. In their respective forms, all studies concluded by consensus the existence of a positive relationship between students' proficiency in English and their academic performance.

However, none of the papers discussed had sought to identify a correlation between students' English language skills (L2) and their respective academic performance in an unrelated discipline. In the context of this research paper, students study their degree subjects in Thai (typical of most university degree courses in Thailand), and presumably therefore, a weaker level of English proficiency should not have a direct negative impact on performance outcomes in their main field of study. While the completion of English language modules is compulsory, English constitutes a minor subject of most degree programmes in Thailand. Within the parameters of this research, students' performance in both English and their respective academic disciplines (measured in terms of G.P.A) are to be compared to ascertain whether high-performing students in foreign language study are synonymously higher achievers across unrelated subjects.

\section{Research Questions}

1. What is the students' level of English proficiency as measured across the following four categories; (1) year group, (2) gender, (3) faculty, and (4) across the entire sample population?

2. What is the students' GPA as measured across the aforementioned categories?

3. What is inferential correlation between the two performance-related variables?

\section{Hypotheses}

On account of the ' $g$ ' factor that is alleged to enter into performance across unrelated cognitive tasks, the following two hypotheses have been formulated:

1. Higher levels of English proficiency levels are expected to be associated with a higher standard of GPA. 
2. The two performance-related variables are expected to be strongly correlated across all categorical measures.

\section{Methodology}

This is a quantitative research study designed to test the relationship between students' ability in foreign language study and overall academic performance (GPA). The sample in this paper encompassed a total of 2,026 students at a university located on the outskirts of Bangkok. The English courses provided by the university are designed to be communicative and do not include essay writing. The focus of the course is to consolidate students' understanding of essential grammar and vocabulary, and to reproduce these forms in communication. Each course is 15 weeks long (one academic term) consisting of 15 English classes which are 2.5 hours in duration. Classes typically range from 20-30 students in size, and most students are categorised as elementary to lower intermediate level learners.

The following data collection tools are to be used to measure English proficiency and overall academic performance in terms of GPA. First of all, English proficiency is scored across two separate criteria which constitute the overall grade; formal examinations and language and communication skills.

1. Formal examinations (55\%): consist of two core components. Firstly, the mid-term assessment (15\%) is a two and a half hour examination which comprises multiple-choice style questions for grammar, vocabulary and reading comprehension. The final examination (40\%) is a significant contribution to the overall grade and also is two and a half hours in duration. The final exam also requires a written output as well as a number of reading comprehension assessments and grammar focused questions. In Thai education, most tests are typically multiple-choice, and the university's formalised assessment structure largely mirrors this typical traditional ideology of testing.

2. Language and Communication (45\%): the English Language Centre at the university strives to introduce a range of communicative exercises to activate students' participation in the learning process, and to enrich an acquisition poor environment (Ellis, 2009), seeing that students are exposed to very little English outside of the classroom. During communicative activities, students are incited to experiment with independent language use relatively free of corrective feedback in order to build confidence and develop fluency.

Academic Performance is measured by grade point average (GPA) which represents the average value of the accumulated final grades earned in course modules over the time. This formally baselines students' academic performance across all courses studied in their respective academic disciplines and facilitates contrastive analysis with English language results. 
Table 1. Scores Conversion

\begin{tabular}{|c|c|c|}
\hline Percentage & Letter Grade & GPA \\
\hline $90 \%$ & $\mathrm{~A}$ & 4 \\
\hline $80 \%$ & $\mathrm{~B}+$ & 3.5 \\
\hline $70 \%$ & $\mathrm{~B}$ & 3 \\
\hline $60 \%$ & $\mathrm{C}+$ & 2.5 \\
\hline $50 \%$ & $\mathrm{C}$ & 2 \\
\hline $40 \%$ & $\mathrm{D}+$ & 1.5 \\
\hline $30 \%$ & $\mathrm{D}$ & 1 \\
\hline
\end{tabular}

The data were analysed through an independent samples t-test for significance testing (0.05); followed by Pearson's correlation coefficient analysis to calculate the degree of linearity between the two sets of performance variables. Furthermore, statistical comparisons also looked to ascertain the significance of profile-related variables within this parameter; examining performance variations according to (1) year group (2) gender, (3) faculty, and (4) across the entire sample population.

\section{Findings/Results}

Prior to answering the research questions set out in this paper, information pertaining to students' demographic profiles across year levels and faculties is required.

Table 2. Profile of the Respondents in Terms of Age, Gender and Course

\begin{tabular}{|c|c|c|c|c|c|c|c|c|c|c|}
\hline & \multicolumn{2}{|c|}{ Engineers } & \multicolumn{2}{|c|}{ Business } & \multicolumn{2}{|c|}{ I.T } & \multicolumn{2}{|c|}{ Vets } & \multirow[b]{2}{*}{$N$} & \multirow[b]{2}{*}{$\begin{array}{c}\text { Total } \\
\%\end{array}$} \\
\hline Age (M) & $F$ & $M$ & $F$ & $M$ & $F$ & $M$ & $F$ & $M$ & & \\
\hline $\begin{array}{l}\text { Level 1: } \\
18.6\end{array}$ & 51 & 412 & 90 & 36 & 12 & 57 & 23 & 10 & 691 & 34.10 \\
\hline $\begin{array}{l}\text { Level 2: } \\
19.55\end{array}$ & 62 & 405 & 106 & 31 & 18 & 59 & 37 & 13 & 731 & 36.10 \\
\hline $\begin{array}{l}\text { Level 3: } \\
20.7\end{array}$ & 59 & 353 & 86 & 29 & 9 & 46 & 15 & 7 & 604 & 29.80 \\
\hline (n) & (172) & $(1,170)$ & (282) & (96) & (39) & (162) & (75) & (30) & $(2,026)$ & \\
\hline$\%$ & 8.5 & 57.8 & 13.9 & 4.7 & 1.92 & 8.0 & 3.7 & 1.5 & & \\
\hline
\end{tabular}

Table 2 displays the students' profile details in relation to age, gender and course of study. The mean age of the students was as follows: year level one (18.6 years), year level two (19.55 years), and year level three (20.7 years). The largest sub group in this study were the engineers $(n=1,342)$ which represented $66.3 \%$ of the overall population, and the smallest sub group was that of the veterinary medicine students $(n=105)$, which comprised merely $5.2 \%$ of the overall population.

As noted in Table 2, the gender-related demographics vary considerably across faculties. Unmistakably, all faculties are demographically unbalanced; IT 
and engineering being overwhelmingly masculine, and business and veterinary science more so feminine.

In order to answer the first two research questions set out in this paper, the following data will ascertain students' level of English proficiency, and GPA, as measured across the following four categories; (1) year group, (2) gender, (3) faculty, and (4) across the entire sample population.

The students English proficiency levels were as follows:

Table 3. Mean English Proficiency Scores: Inter-Year Level Comparisons

\begin{tabular}{|l|c|c|c|c|}
\hline \multicolumn{1}{|c|}{ Year Level } & $\mathbf{N}$ & $\mathbf{M}(\mathbf{\%})$ & $\mathbf{P}$ & Result \\
\hline Year One & 691 & 52.77 & & \\
\hline & & & $<0.01$ & Sig $\mathrm{p}<0.05$ \\
\hline Year Two & 731 & 48.96 & & \\
\hline Year Two & 731 & 48.96 & & \\
\hline & & & $<0.01$ & Sig $\mathrm{p}<0.05$ \\
\hline Year Three & 604 & 44.81 & & \\
\hline
\end{tabular}

Table 3 indicates that students scored higher levels of attainment in their first year of study ( $\mathrm{M}=\mathrm{C}$ grade). Nonetheless, the second year students performed to a significantly lower standard than the first year students, as mirrored in the $\mathrm{p}$ value of $<0.01$. Likewise, identical $P$ value readings, were observed between second and third year students; inferring that the standard of English language attainments declined significantly as a function of year of study (and therefore age).

Table 4. English Proficiency In Relation To Gender

\begin{tabular}{|l|c|c|c|c|c|}
\hline Gender & $\mathbf{N}$ & $\mathbf{M}(\boldsymbol{\%})$ & SD & P & Result \\
\hline F & 585 & 56.56 & 18.94 & & \\
\hline & & & & $<0.01$ & Sig p $<0.05$ \\
\hline M & 1439 & 45.96 & 16.37 & & \\
\hline
\end{tabular}

With respect to gender, Table 1.4 shows that the means of the two sets of English proficiency scores were significantly different, as females ostensibly outperformed their male counterparts, as reflected in the $p$ value $(<0.01)$. Given such a contrast in English language proficiency, it would be of interest to see if female students also outclassed their male peers in non-language subjects, which is reviewed later in this section.

Table 5. English Proficiency According to Faculty

\begin{tabular}{|l|c|c|c|c|}
\hline Mean of N & Faculty & $\mathbf{M}(\boldsymbol{\%})$ & $\mathbf{P}$ & Result \\
\hline \multirow{4}{*}{49.02} & Engineers & 46.61 & $<0.01$ & $\operatorname{Sig} \mathrm{p}<0.05$ \\
\cline { 2 - 5 } & Business & 51.04 & 0.0424 & $\operatorname{Sig} \mathrm{p}<0.05$ \\
\cline { 2 - 5 } & I.T & 46.86 & 0.102 & Not Sig $\mathrm{P}<0.05$ \\
\cline { 2 - 5 } & Vets & 75.94 & $<0.01$ & $\operatorname{Sig} \mathrm{p}<0.05$ \\
\hline
\end{tabular}

As displayed in Table 5, when individually comparing the means of each faculty with that of the overall sample population, differing levels of attainment were noted across faculties. Only the I.T students' average level of English 
proficiency was akin to the mean value $(\mathrm{p}=0.012)$. In contrast, business students $(\mathrm{p}=0.0424)$ and particularly veterinary medicine students $(\mathrm{p}=<0.01)$ performed to a significantly higher standard than the overall mean. Nonetheless, the engineers' English language performance was significantly below the average benchmark $(\mathrm{p}=<0.01)$.

Having analysed the students' English proficiency levels, their respective GPA attainments were determined as follows:

Table 6. Academic Performance According to Year Group

\begin{tabular}{|l|c|c|c|c|}
\hline Year Level & $\mathbf{N}$ & $\mathbf{M}(\boldsymbol{\%})$ & $\mathbf{P}$ & Result \\
\hline Year One & 691 & 68.06 & & \\
\hline & & & $<0.01$ & Sig $\mathrm{p}<0.05$ \\
\hline Year Two & 731 & 63.35 & & \\
\hline Year Two & 731 & 63.35 & & Sig $\mathrm{p}<0.05$ \\
\hline & & & 0.0396 & \\
\hline Year Three & 604 & 61.68 & & \\
\hline
\end{tabular}

Table 6 establishes that, in concert with English proficiency results, GPA attainments also progressively deteriorated in succession across the three year levels; as mirrored in $\mathrm{p}=<0.01$ between years one and two, and subsequently $\mathrm{p}=$ 0.0396 between years two and three. This manifests that academic performance deteriorated significantly as a function of year level.

Table 7. Academic Performance (GPA) According to Gender

\begin{tabular}{|l|c|c|c|c|c|}
\hline Gender & N & M(\%) & SD & P- Value & Result \\
\hline F & 585 & 69.46 & 15.49 & & \\
\hline & & & & $<0.01$ & Sig $\mathrm{p}<0.05$ \\
\hline M & 1439 & 62.43 & 14.56 & & \\
\hline
\end{tabular}

The data in Table 7 shows that females scored saliently higher GPAs than their male counterparts, as denoted in the $p$ value $(<0.01)$ between the two sets of results. The fact that females scored remarkably higher GPAs, along with significantly higher levels of English language proficiency, begins to contribute to the argument that more proficient English language skills are linked to higher academic achievements. Furthermore, as a result of the females' superior achievements in both English and GPAs, investigative action is encouraged to study the effect of the gender variable in a separate broader context. 
Table 8. Academic Performance (GPA) According to Faculty

\begin{tabular}{|l|c|c|c|c|}
\hline Mean of N & Faculty & $\mathbf{M}(\boldsymbol{\%})$ & P Value & Result \\
\hline \multirow{4}{*}{64.57} & Engineers & 63.15 & 0.0082 & $\operatorname{Sig} \mathrm{p}<0.05$ \\
\cline { 2 - 5 } & Business & 65.65 & 0.1930 & Not Sig $\mathrm{p}<0.05$ \\
\cline { 2 - 5 } & I.T & 63.87 & 0.522 & Not Sig $\mathrm{p}<.05$ \\
\cline { 2 - 5 } & Vets & 77.49 & $<0.01$ & $\operatorname{Sig} \mathrm{p}<0.05$ \\
\hline
\end{tabular}

Table 8 specifies that the veterinary medicine students were the only group to have performed above the average standard of the population $(\mathrm{p}=<0.01)$. Contrarily, the average GPA of the engineers was considered to be significantly inferior to the population mean $(\mathrm{p}=0.0082)$ in spite of displaying similar averages (63.15\% vis-à-vis 64.57\%). Nonetheless, the Business and I.T students' average academic performance was in harmony with the population mean, as reflected in the respective $p$ values of 0.1930 and 0.522 .

The following data will be utilised to answer the ultimate research question in this paper pertaining to the relationship between students' English proficiency and GPA attainments.

Table 9. Relationship between English proficiency and Academic performance

\begin{tabular}{|l|c|c|c|c|c|c|}
\hline Variable & $\mathbf{N}$ & $\mathbf{M}(\boldsymbol{\%})$ & SD & P & Result & R \\
\hline English & & $49.02 \%$ & 17.91 & & & \\
\hline & 2,026 & & & $<0.01$ & Sig p $<0.05$ & 0.653 \\
\hline GPA & & $64.57 \%$ & 14.87 & & & \\
\hline
\end{tabular}

Table 9 reveals that the students' average level of English language proficiency skills (49.02\%) is significantly inferior to their overall average level of academic performance $(\mathrm{GPA}=64.57 \%)$; as highlighted in $\mathrm{p}=<0.01$. Nonetheless, the $r$ value, as calculated from the Pearson's correlation coefficient analysis $(r=$ 0.653) suggests that the two sets of variables are positively correlated, broadly insinuating that higher English proficiency levels are associated with higher GPA achievements.

Table 10. Relationship between English Proficiency and Academic Performance according to faculty

\begin{tabular}{|c|c|c|c|c|c|c|}
\hline Faculty & Variable & N & M $(\%)$ & P & Result & R \\
\hline & English & & 46.61 & & & \\
\hline Engineers & & 1,342 & & $<0.01$ & Sig $\mathrm{p}<0.05$ & 0.636 \\
\hline & GPA & & 63.15 & & & \\
\hline & English & & 51.04 & & & \\
\hline Business & & 378 & & $<0.01$ & Sig p $<0.05$ & 0.611 \\
\hline & GPA & & 65.65 & & & \\
\hline I.T & English & & 46.86 & & & 0.579 \\
\hline & GPA & 201 & & $<0.01$ & Sig p $<0.05$ & \\
\hline & English & & 63.87 & & & \\
\hline Vets & & 105 & & 0.4475 & Not Sig p $<0.05$ & 0.354 \\
\hline & GPA & & 77.49 & & & \\
\hline
\end{tabular}


As displayed in Table 10, performances varied considerably across faculties in terms of both English proficiency and GPA attainments. With reference to the Engineers, business students and the I.T group, there was a significant difference between the two sets of performance related variables $(p=<0.01)$. Nevertheless, the $r$ value readings infer a positive relationship given that the readings remained constant between $r=0.636$ and $r=0.579$ across the three faculties. Inversely, when measuring the relationship between English proficiency and GPA for the veterinary medicine students, $r=0.354$ insinuated a comparatively weak correlation.

However, the means of the two performance-related variables were not statistically different $(\mathrm{p}=0.4475)$, meaning that both performances were of a similar standard. Furthermore, higher English proficiency scores were associated with higher GPAs across every measure, adding further support to the interlinked nature of the two variables. This is reflected in the fact that the faculty demonstrative of the most proficient English skills (vets) simultaneously achieved the highest GPA, and on the contrary, the faculty least proficient in English (engineers) correspondingly attained the lowest GPA attainments.

\section{Discussion}

The following three factors (demographics, performance, and, curricular issues) will be discussed in further detail to ascertain the causes of declining academic standards, and, possible solutions to help forestall this problematic trend.

Demographics: while the strength of this experiment was the size and scale of the participants, which was considerably larger than the studies reviewed earlier, the sample did present some limitations. As noted a priori, every faculty was demographically imbalanced and may have led to biased readings, as manifested in the fact that female engineers only accounted for $14 \%$ of that individual subgroup. From a wider perspective, $57.8 \%$ of the entire population constituted male engineers, which over represents this stratum within the context of this experiment. Further to which, engineers are not commonly typified as avid scholars of English, (as reflected in the results), thus the size of this sub-cluster negatively influenced the mean score for both performance variables relative to the entire sample population. Subsequent research may contemplate faculties comprising similar student numbers and gender-related demographics.

Academic performance: interestingly, students in the foundation year performed at their highest, and standards declined progressively thereafter. This may have pertained to two central factors:

1. Students' gradual disengagement in studying English owing to a growing disinterest, or, the choice to prioritise their main field of study. That said, students' GPA also inexplicably recorded successive deterioration as a function of year group. 
2. First year study requirements are considerably more basic and the assessments are simpler to master. Moreover, a large number of students may struggle to increase their commitment to subjects as they become more complex.

Curricular enrichment: the identified need for curricular enrichment is inspired by the observation that students displaying higher levels of English proficiency achieve higher GPAs. Therefore, enhancing curricular design to highlight the development of English language proficiency would presumably lead to broad improvements in GPAs as a result of the cognitive flexibility acquired in the process of achieving higher L2 competence.

The current syllabus focuses on coverage based learning with painstaking attention dedicated to grammar and vocabulary in order to prepare for mid-term and end-term examinations (mostly in the form of multiple-choice format). Nonetheless, students often appear underprepared for speaking tests, fail to understand what is required of them, and, how to perform at satisfactory levels (despite efforts to implement communicative activities throughout the term). In order to increase performance outcomes in this form assessment, students would be urged to experience using the language meaningfully, and to affect this nature of change, this paper proposes the introduction of task-based language teaching (TBLT). This would entail moving the syllabus away from instructing specific grammatical forms towards the processing of semantic and pragmatic meaning (Ellis, 2009, p. 223).

In TBLT students become language "users", as opposed to language "learners" (Ellis 2001), and learning objectives focus on the learning process; aiming to cultivate purposeful and functional language use to express meaning to complete tasks. In addition to which, owing to the mixed ability demographics of the classrooms, group-based activities could help learners reproduce content and elaborate independently, facilitated by teacher guidance. Vygotsky (1978) maintained that interaction with senior peers is an effective means of enhancing the learning process through cooperative learning exercises where less competent learners are able to develop with assistance from more skilful peers. Further to which, Larsson (2001) adds that the importance of social interaction in task-based learning is "positively affected", and that "being an integral part of the group also motivates students to learn in a way that the prospect of a final examination rarely manages to do".

\section{Conclusions}

The most inferential generalisation from the results is that the higher the students' English proficiency skills, the higher the respective level of academic achievement; as supported by the positive correlation between the two variables ( $\mathrm{r}$ $=0.653$ ). These findings lend firm support to Spearman's ' $g$ ' factor theory (1904), which summarises positive correlations across a range of cognitive tasks, positing that an individual's performance on one given cognitive task tends to be comparable 
to that of other dissimilar tasks. Therefore, if administrators were to prioritise and proactively integrate second language study into academic programmes, the cognitive enhancements derived from such a measure may subsequently enhance academic achievement in broader terms.

\section{References}

Adams, T.L. (2003). Reading mathematics: More than words can say. The Reading Teacher, 56(8), 786-795.

Armstrong, P.W., \& Rogers, J.D. (1997). Basic skills revisited: The effects of foreign language instruction on reading, math, and language arts. Learning Languages, 2(3), $20-31$.

Bialystok, E., \& Hakuta, K. (1994). In other words: The science and psychology of second language acquisition. New York: Basic Books.

Ellis, R. (2001). Focussing on form: Towards a research agenda. In W. Renandya and N. Sunga (eds). Language Curriculum and Instruction in Multicultural Societies (pp. 123-144). Singapore: SEAMEO Regional Language Centre.

Ellis, R. (2009). Task-based language teaching: sorting out the misunderstandings. International of Applied Linguistics, 19(3), 221-246.

Fuchsen, M. (Spring, 1989). Starting language early: A rationale. FLESNEWS, 2(3), 1, 67.

Gardner, H. (1995). Reflections on Multiple Intelligences: Myths and Messages. $\quad$ Phi Delta Kappan, 77, 200-209.

Gardner, H. (1998). A Reply to Perry D. Klein's 'Multiplying the problems of intelligence by eight'. Canadian Journal of Education, 23(1), 96-102.

Gardner, H. (1999). Intelligence reframed: Multiple intelligences for the $21^{\text {st }}$ century. New York: Basic Books.

Gottfredson, L. (1998). The General Intelligence Factor. Scientific American, 24-30.

Hakuta, K. (1984). The Causal Relationship between the Development of Bilingualism, Cognitive Flexibility, and Social-Cognitive Skills in Hispanic Elementary School Children. Final report prepared for the National Institute of Education.

Jensen, A. (1998). The g factor and the design of education. In R.J. Sternberg \& W.M. Williams (Eds.), Intelligence, instruction, and assessment: Theory into practice (pp. 111-131). Mahwah, NJ: Lawrence Erlbaum.

Kamphaus, R.W., Winsor, A.P., Rowe, E.W., \& Kim, S. (2005). A history of intelligence test interpretation. In D.P. Flanagan \& P.L. Harrison (Eds.), Contemporary intellectual assessment: Theories, tests, and issues (pp. 23-38). New York: Guilford.

Kamrul Hasan, M., \& Moniruzzaman Akhand, M. (2014). EFL Language Students English Language Proficiency and Their Academic Achievement. ABAC Journal, 34(2), 6470.

Kessler, C. Quinn M.E. (1980). Positive Effects of Bilingualism on Science ProblemSolving Abilities. Proceedings of the Annual Georgetown University Round Table on Languages and Linguistics, Georgetown University, Washington, D.C.

Larsson, J. (2001). Problem-Based Learning: A Possible Approach to Language Education? Polonia Institute. Jagiellonian University.

MacGregor, M., Price, E. (1999). Aspects of language proficiency and algebra learning. Journal for Research in Mathematics Education, 30(4), 449-67.

Masciantonio, R. (1977). Tangible Benefits of the study of Latin: A review of Research. Foreign Language Annals, 10(4). 
Myers, D.G (2009). Psychology: Ninth Edition in Modules. USA: Worth Publishers.

Pedersen, N.L., Plomin, R., \& McClearn, G.E. (1994). Is there G beyond g? Is there genetic influence on specific cognitive abilities independent of genetic influence on general cognitive ability? Intelligence, 18(2), 133-143).

Rafferty, E. (1986). Second Language Study and Basic Skills in Louisiana. Louisiana State Dept. of Education, Baton Rouge. Office of Research and Development.

Saunders, B. (1998). Revisiting basic colour terms. Proceedings for the conference of Anthropology and Psychology. St. John's College, Cambridge, U.K.

Spearman, C. (1904). General Intelligence Objectively Determined and Measured. The American Journal of Psychology, 15(2), 201-292.

Wiley, P.D. (1985). Foreign Language Learning in the Elementary Schools: A Comparison of Three Language Programs. The Modern Language Journal, 69(1), 44-54.

Vygotsky, L. (1978). Mind in society: The development of higher psychological processes. USA: Harvard University Press.

Wakefield, D. (2000). Math as a Second Language. The Education Forum 64, 272-279. 
